\section{Sympathy from students}

Re: "No longer free for all."1 As a representative of Canadian medical students studying abroad, I want to thank the CMAJ for being our main source for Canadian-specific health matters. For years the CMAJ has served us for free, but we know all too well that costs of business are mounting. If fees are required for us to view $C M A J$ material less than 12 months old, we Canadians in Ireland will become less current; however, that is a small price to pay to help ensure that the journal maintains both its existence and level of quality.

Rob Obara, first-year medical student Trinity College, Dublin, Ireland

\section{REFERENCE}

1. Hébert PC. No longer free for all. CMAJ 2009;181: E244.

For the full letter, go to: www.cmaj.ca/cgi/eletters /181/11/E244\#246110

DOI:10.1503/cmaj.110-2001

\section{Tobacco lawsuits}

Re: "Destroyed documents: uncovering the science that Imperial Tobacco Canada sought to conceal."1 At the end of September, the Ontario government became the third province to file a claim against the tobacco companies to recover health care costs associated with smoking. Mere money will not bring back to life the million or so Canadians killed by tobacco, nor will it prevent hundreds of thousands of tobacco-caused deaths that will occur. Provincial litigators need to rethink their strategies. There are many healthrelated goals that could guide these lawsuits. They include a settlement that requires plain packaging of cigarettes, a reduced number of retail outlets and increased controls on the remaining ones and more support for smoking cessation programs. But these measures, important as they are, do not address the central problem: Tobacco companies continue to profit from a deadly product that will kill half its life- long users. The most important service provincial litigators could render to all Canadians would be to demand that tobacco companies be obliged to fix this problem. It is time for litigators to ask the courts to require tobacco companies to phase out tobacco.

Neil Collishaw, research director

Physicians for a Smoke-Free Canada

\section{REFERENCE}

1. Hammond D, Chaiton M, Lee A, et al. Destroyed documents: uncovering the science that Imperia Tobacco Canada sought to conceal. CMAJ 2009;181:691-8.

For the full letter, go to: www.cmaj.ca/cgi/eletters /181/10/691\#244361

DOI:10.1503/cmaj.110-2004

\section{Lack of physician scientists}

Dr. Laberge and her colleagues ${ }^{1}$ touch a very important question. One of the roots may be - at least in Sweden and Finland - a decrease in the number of medically qualified scientists. The basic sciences have difficulties attracting young medical students or recent graduates to do research and, therefore, future clinical leaders do not have hands-on experience on the creation and application of modern biomedical methods and concepts. Sweden has created special research-orientated internships for young physicians with early success, although the impact in the long term remains to be seen. It is felt that future clinicians should have a more active role in the creation of new biomedical primary discoveries so that they could more fully understand and use translational research.

Heikki Savolainen, professor

Department of Occupational Safety and Health, Tampere, Finland

\section{REFERENCE}

1. Laberge S, Albert M, Hodges BD. Perspectives of clinician and biomedical scientists on interdisciplinary health research. CMAJ 2009;181:797-803.

For the full letter, go to: www.cmaj.ca/cgi/eletters /181/11/797\#245668

DOI:10.1503/cmaj.110-2005

\section{Be careful about timelines}

Tom Koch ${ }^{1}$ precisely described the negative repercussions of suggesting to a patient that the end is near. Any discussion that places precise time frames (three to six months) is heard as a death sentence. I tell my undergraduate medical students never to use a number or time frame when discussing end of life. Discuss timing in days to weeks, weeks to months, or months to years. I always follow such estimations with a comment about the difficulty in predicting death. Even after 16 years of experience in oncology, I am occasionally off by weeks or more. Often the desire to know when the end is near is pragmatic. There may be wills to amend, the need to sell a residence, organize finances, or the desire to have family near (many of whom must come from distant locations and take time from work). Find out what these worries or concerns are, and then arrange appropriate support such as a social work consultation.

\section{Christopher Leighton MD}

University of Windsor Campus

Schulich School of Medicine \& Dentistry

Windsor, Ont.

\section{REFERENCE}

1. Koch T. End of life, year after year after year. CMAJ 2009; 181:868.

For the full letter, go to: www.cmaj.ca/cgi/eletters /181/11/868\#245436

DOI:10.1503/cmaj.110-2007

\section{A sea of salt}

I read with some bemusement the excellent review article "Effective population-wide public health interventions to promote sodium reduction." the authors are to be commended on their broad overall perspective, a cynical person might suggest that they might temper their enthusiasm by visiting any of our local supermarkets. If the goal is to truly try to limit sodium consumption to $1200-1500 \mathrm{mg}$ a day as well as having no single food item contain more than $10 \%$ of the daily total, 